\title{
Validation of R6 using finite element analyses of cracked cylinders under thermal loading
}

\author{
Mr R D Patel, MEng (Hons), CEng, MIMechE \\ British Energy Generation Ltd, Barnett Way, Barnwood, Gloucester, \\ GL4 3RS, UK. Tel: +44(0) 1452653716 Fax: +44 (0) 1452653025 \\ E-mail: rajesh.patel@british-energy.com
}

\begin{abstract}
This paper presents validation of the treatment of secondary stresses within Revision 4 of the R6 assessment procedure using finite element analyses of cracked cylinders under thermal loading. Cylinder with a fully-circumferential internal crack and a part-circumferential external surface crack are considered as model examples. The crack driving force values obtained from cracked-body finite element analyses are compared to values obtained using simplified uncracked-body routes within R6. The secondary stress is applied using a temperature gradient. Various temperature loadings and crack sizes have been examined. Also, work performed by the Central Research Institute of Electric Power Industry (CRIEPI) in Japan, which has examined the same geometries, has been compared to the present finite element results in some instances. It is concluded that for the cylinder with a fully-circumferential internal crack the R6 routes are conservative when the thermal load is applied as an axially linear or radially non-linear temperature distribution. The R6 routes are generally conservative when the thermal load is applied as a radially linear temperature distribution, and is only very slightly unconservative in some of the cases. Good agreement is obtained between the present work and the CRIEPI data.
\end{abstract}

\section{INTRODUCTION}

Integrity assessments of structures containing defects are routinely performed using the R6 procedure [1]. R6 uses a failure assessment diagram (FAD) to assess the proximity of the component to failure by fast fracture or plastic collapse. Two parameters, $\mathrm{L}_{\mathrm{r}}$ and $\mathrm{K}_{\mathrm{r}}$, are evaluated. If the assessment point $\left(\mathrm{L}_{\mathrm{r}}, \mathrm{K}_{\mathrm{r}}\right)$ lies outside the failure assessment curve $\mathrm{K}_{\mathrm{r}}=\mathrm{f}\left(\mathrm{L}_{\mathrm{r}}\right)$ on the FAD, then failure is conceded. When using R6, it is necessary to categorise the applied loading as either primary or secondary. Pressure or applied mechanical loads are categorised as primary because they are loadcontrolled, and can therefore cause plastic collapse of the structure. Residual and thermal stresses are normally classified as secondary because they do not contribute to plastic collapse. This paper deals with thermal (secondary) loading only and primary loads will not be discussed. When 
secondary stresses act alone $\mathrm{L}_{\mathrm{r}}=0$ and $\mathrm{f}\left(\mathrm{L}_{\mathrm{r}}\right)=1$. The parameter $\mathrm{K}_{\mathrm{r}}$ is then evaluated using Section II.6 of R6 and failure is conceded if $\mathrm{K}_{\mathrm{r}} \geq 1$. Specifically, for secondary stresses alone, $\mathrm{K}_{\mathrm{r}}$ is defined by:

$$
\mathrm{K}_{\mathrm{r}}=\mathrm{K}_{\mathrm{r}}^{\mathrm{s}}=\mathrm{K}_{\mathrm{J}}^{\mathrm{s}} / \mathrm{K}_{\text {mat }}
$$

where $\mathrm{K}_{\text {mat }}$ is the material fracture toughness and $\mathrm{K}_{\mathrm{J}}^{\mathrm{s}}$ is an effective stress intensity factor for secondary stress. Section II.6 gives advice for determining $\mathrm{K}_{\mathrm{J}}^{\mathrm{s}}$ based on simplified methods.

In this paper Section II.6 of R6 is validated using finite element (FE) analyses of cylinders under thermal loading. The crack driving force values from cracked-body FE analyses are compared to values obtained using the simplified routes within R6 Section II.6. In addition, work performed by the Central Research Institute of Electric Power Industry (CRIEPI) in Japan is also presented. The crack driving forces obtained from the CRIEPI crackedbody analyses are compared to the present results in some cases.

\section{THE R6 APPROACH FOR SECONDARY STRESSES}

In this section, three methods for determination of $\mathrm{K}_{\mathrm{J}}^{\mathrm{s}}$ are described. The first two are approximate methods in R6 Section II.6 which use inelastic and elastic analysis of the uncracked-body in conjunction with weight function solutions for $\mathrm{K}$. The third is the use of cracked-body inelastic analysis which is used to assess the accuracy of the R6 methods.

\section{Uncracked-body $\mathrm{R} 6$ inelastic route}

Elastic-plastic uncracked-body FE analysis is performed to obtain the relevant stress and strain fields. A stress intensity factor, $K_{\sigma}^{s}$, is obtained from the inelastic stress field. A stress intensity factor, $\mathrm{K}_{\varepsilon}^{\mathrm{s}}$, due to the "pseudo-stress" $\widetilde{\sigma}_{\mathrm{yy}}$ is also derived from the inelastic mechanical strain field:

$$
\widetilde{\sigma}_{\mathrm{yy}}=[\mathrm{E} /(1+v)(1-2 v)]\left[(1-v) \varepsilon_{\mathrm{yy}}+v\left(\varepsilon_{\mathrm{xx}}+\varepsilon_{\mathrm{zz}}\right)\right]
$$

where $\mathrm{E}$ and $v$ are the elastic constants with the y-axis normal to the defect in the $\mathrm{x}-\mathrm{z}$ plane. Here, $\mathrm{K}_{\sigma}^{\mathrm{s}}$ and $\mathrm{K}_{\varepsilon}^{\mathrm{s}}$ were calculated using the analysis tool R6Code [2]. $\mathrm{K}_{\mathrm{J}}^{\mathrm{s}}$ is then estimated at the actual crack size a from: 


$$
\mathrm{K}_{\mathrm{J}}^{\mathrm{s}}(\mathrm{a})=\left(\mathrm{a}_{\text {eff }}^{\sigma} \mathrm{a}_{\text {eff }}^{\varepsilon} / \mathrm{a}^{2}\right)^{1 / 4}\left(\mathrm{~K}_{\sigma}^{\mathrm{s}}(\mathrm{a}) \mathrm{K}_{\varepsilon}^{\mathrm{s}}(\mathrm{a})\right)^{1 / 2}
$$

where:

$$
\begin{aligned}
& a_{\text {eff }}^{\sigma}=a+(1 / 2 \pi \beta)\left(K_{\sigma}^{\mathrm{s}}(\mathrm{a}) / \sigma_{\mathrm{y}}\right)^{2} \\
& \mathrm{a}_{\text {eff }}^{\varepsilon}=\mathrm{a}+(1 / 2 \pi \beta)\left(\mathrm{K}_{\varepsilon}^{\mathrm{s}}(\mathrm{a}) / \sigma_{\mathrm{y}}\right)^{2}
\end{aligned}
$$

with $\beta=1$ or 3 in plane stress, plane strain, respectively. For axisymmetric conditions, $\beta=3$ is used. This value is used for the cases analysed.

\section{Uncracked-body $R 6$ elastic route}

In the absence of an elastic-plastic analysis, an estimate of $\mathrm{K}_{\mathrm{J}}^{\mathrm{s}}$ is given in R6 by:

$$
\mathrm{K}_{\mathrm{J}}^{\mathrm{s}}=\left(\mathrm{a}_{\text {eff }} / \mathrm{a}\right)^{1 / 2} \mathrm{~K}_{\mathrm{I}}^{\mathrm{s}}(\mathrm{a})
$$

where:

$$
a_{\text {eff }}=a+(1 / 2 \pi \beta)\left(K_{I}^{\mathrm{s}}(a) / \sigma_{y}\right)^{2}
$$

and $\mathrm{K}_{\mathrm{I}}^{\mathrm{s}}$ is the linear elastic stress intensity factor.

\section{Cracked-body R6 inelastic route}

Values of $\mathrm{J}$ may be obtained by performing FE analyses using cracked-body meshes. $\mathrm{K}_{\mathrm{J}}^{\mathrm{s}}$ is then calculated from $\mathrm{J}$ using the relationship:

$$
K_{J}^{\mathrm{s}}(J)=\left(E^{/} J^{\mathrm{s}}\right)^{1 / 2}
$$

$\mathrm{E}^{\prime}=\mathrm{E} /\left(1-\mathrm{v}^{2}\right)$ for plane strain and axisymmetry, $\mathrm{E}^{\prime}=\mathrm{E}$ for plane stress

\section{COMPONENT GEOMETRIES}

The first geometry considered is a cylinder with internal radius, $\mathrm{R}_{\mathrm{i}}=$ $100 \mathrm{~mm}$, section thickness, $\mathrm{t}=10 \mathrm{~mm}$ and a fully-circumferential internal crack of depth a. Figure 1 shows the ABAQUS [3] FE cracked-body mesh for $\mathrm{a} / \mathrm{t}=0.25$. This mesh consists of 688 ABAQUS CAX8R axisymmetric 8 -noded elements and 2211 nodes. The mesh is analysed in axisymmetric 
conditions. The uncracked cylinder was modelled using this mesh but with the crack face nodes constrained in the axial direction.
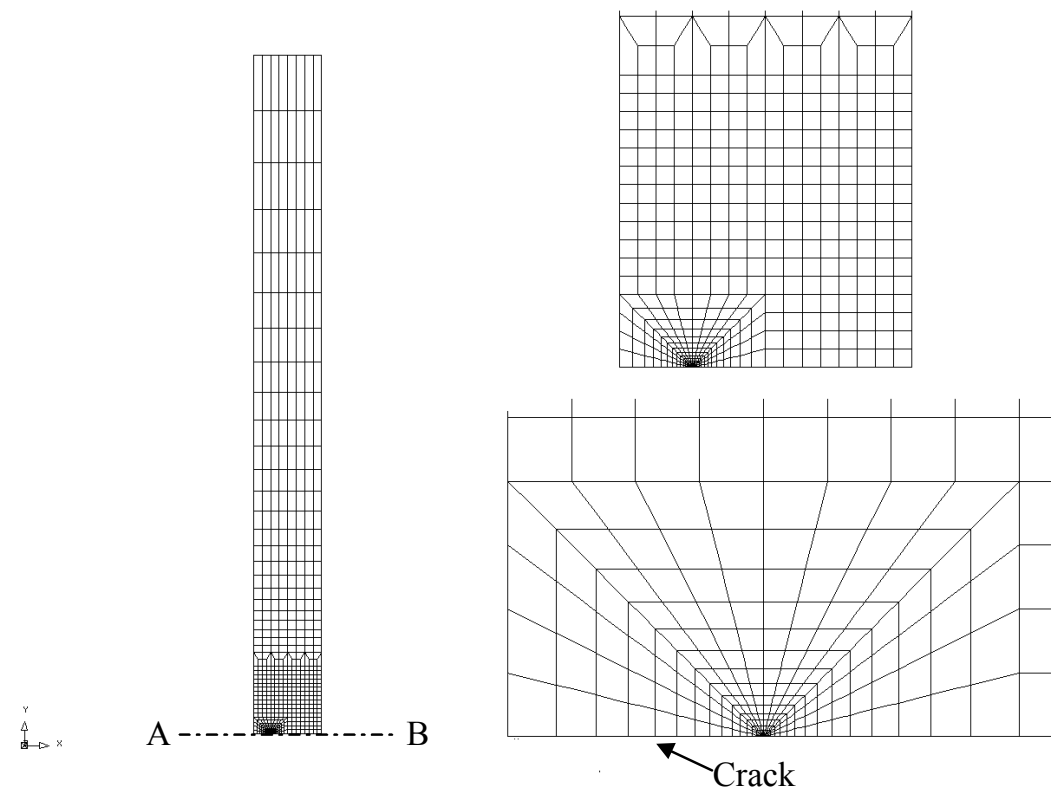

Figure 1: Axisymmetric FE mesh of cylinder with a fully-circumferential internal crack with $\mathrm{a} / \mathrm{t}=0.25$. $\mathrm{AB}$ is the symmetry plane.

The second geometry is the same cylinder but with a partcircumferential external semi-elliptical surface crack, with ratio of crack depth to half length, a/c. The FE analyses for this component were performed by CRIEPI.

TABLE I: Material properties used in ABAQUS analyses

\begin{tabular}{||l|c||}
\hline \multicolumn{2}{|c||}{ Material Properties } \\
\hline Conductivity & $14.12 \times 10^{-3} \mathrm{~W} / \mathrm{mm} /{ }^{\circ} \mathrm{C}$ \\
\hline Specific heat & $492 \mathrm{~J} / \mathrm{kg} /{ }^{\circ} \mathrm{C}$ \\
\hline Density & $7.966 \times 10^{-6} \mathrm{~kg} / \mathrm{mm}^{3}$ \\
\hline Thermal Expansion & $1.456 \times 10^{-5} \mathrm{~mm} / \mathrm{mm} /{ }^{\circ} \mathrm{C}$ \\
\hline Young's Modulus & $154000 \mathrm{~N} / \mathrm{mm}^{2}$ \\
\hline Poisson's Ratio & 0.3 \\
\hline
\end{tabular}

Table I shows the material properties used. The limit of proportionality was taken as $196 \mathrm{MPa}$ and the $0.2 \%$ proof stress, $\sigma_{\mathrm{y}}$, was $230.22 \mathrm{MPa}$. Linear strain hardening was assumed. The same material description was used in 
the CRIEPI analyses, the only difference being that the thermal expansion coefficient was taken to be $2 \times 10^{-5} \mathrm{~mm} / \mathrm{mm} /{ }^{\circ} \mathrm{C}$.

\section{FINITE ELEMENT ANALYSES}

FE analyses using ABAQUS [3] were performed on both the uncrackedbody mesh, to generate the stress and strain fields required by the R6 inelastic route, and the cracked-body mesh, to determine $\mathrm{J}$.

Further ABAQUS analyses were performed and these results were compared to the cracked-body FE $\mathrm{J}$ values obtained from CRIEPI, which used the MARC FE program. For these cases a thermal expansion coefficient of $2 \times 10^{-5} \mathrm{~mm} / \mathrm{mm} /{ }^{\circ} \mathrm{C}$ was used.

\section{Cylinder with fully-circumferential internal crack}

Three crack sizes, $\mathrm{a} / \mathrm{t}=0.25,0.50$ and 0.75 , and three loading conditions were examined. To apply the axially linear temperature distribution, an initial temperature of $20^{\circ} \mathrm{C}$ was applied to the entire cylinder. Temperature boundary conditions were applied so that the nodes on the symmetry plane (see Fig. 1) were set to $20^{\circ} \mathrm{C}$ and the nodes at the top of the cylinder were set to $620^{\circ} \mathrm{C}$. A transient analysis was then run until a steady state was achieved and the temperature history was used as the loading in the thermal stress analysis. The radially linear temperature distribution was applied in the same manner as the axially linear temperature distribution but with different temperature boundary conditions. For the radially non-linear temperature distribution only one thermal-structural analysis was performed to evaluate the crack driving forces.

For the three temperature distributions the magnitude of the temperature difference, $\Delta \mathrm{T}$, was varied to provide different levels of plasticity. For the axially linear temperature distribution, $\Delta \mathrm{T}$ values of $600^{\circ} \mathrm{C}, 700^{\circ} \mathrm{C}$ and $800^{\circ} \mathrm{C}$ were used. For the radially linear and non-linear temperature distributions, $\Delta \mathrm{T}$ values of $200^{\circ} \mathrm{C}, 300^{\circ} \mathrm{C}$ and $400^{\circ} \mathrm{C}$ were employed.

\section{Cylinder with part-circumferential external surface crack}

Only one crack size and loading condition were examined for the partcircumferential external surface crack. The crack size was $\mathrm{a} / \mathrm{t}=0.25$ and $\mathrm{a} / \mathrm{c}$ $=0.50$. A temperature difference, $\Delta \mathrm{T}$, of $200^{\circ} \mathrm{C}$ was used to define the temperature distribution. For this case the $\mathrm{FE}$ analysis was performed by CRIEPI and the data were used to perform the simplified R6 assessments 
and to compare these to the cracked-body crack driving forces calculated by CRIEPI.

\section{RESULTS AND DISCUSSION}

\section{Fully-circumferential internal crack}

Figure 2 shows the elastic-plastic uncracked-body pseudo and yy stresses across the symmetry plane $\mathrm{AB}$ for the axially linear temperature distribution. The pseudo and yy stresses are positive up to $5 \mathrm{~mm}$ through the thickness from the internal surface of the cylinder and then are negative to the outer wall. As $\Delta \mathrm{T}$ increases, the peak stresses and stress ranges increase. Similar stress distributions are obtained for the radially-linear and non-linear cases.
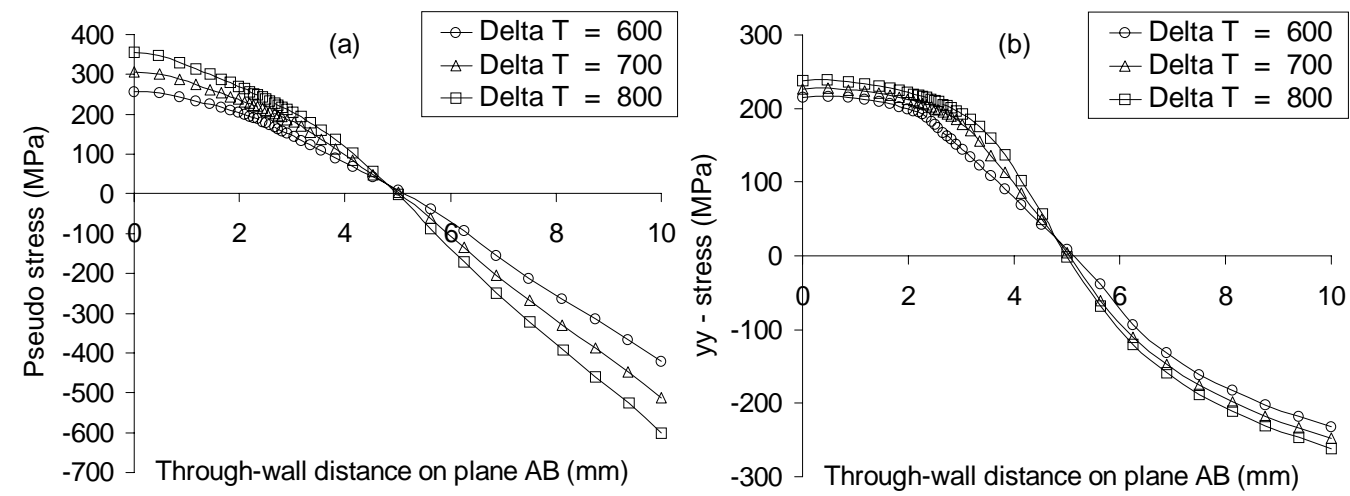

Figure 2: Elastic-plastic uncracked-body (a) pseudo and (b) yy stress, across $\mathrm{AB}$ plane for the axially linear temperature distribution.

Table II shows the values of stress intensity factor derived from the R6 inelastic and elastic routes and from the cracked-body analysis for the fullycircumferential internal crack for the three temperature distributions. Results for one value of $\Delta \mathrm{T}$ are tabulated in each case. 
TABLE II: Values of K derived from R6 elastic and inelastic routes and from crackedbody FE analyses. Cylinder with fully-circumferential internal crack

\begin{tabular}{|c|c|c|c|c|c|}
\hline $\mathrm{a} / \mathrm{t}$ & $\begin{array}{c}\mathrm{K}_{\sigma}^{\mathrm{s}} \\
\left(\mathrm{MPa} \cdot \mathrm{m}^{1 / 2}\right)\end{array}$ & $\begin{array}{c}\mathrm{K}_{\varepsilon}^{\mathrm{s}} \\
\left(\mathrm{MPa} \cdot \mathrm{m}^{1 / 2}\right)\end{array}$ & $\begin{array}{c}\text { Elastic } \\
\mathrm{K}_{\mathrm{J}}^{\mathrm{s}} \\
\left(\mathrm{MPa} \cdot \mathrm{m}^{1 / 2}\right)\end{array}$ & $\begin{array}{c}\text { Elastic-plastic } \\
\mathrm{K}_{\mathrm{J}}^{\mathrm{S}} \\
\left(\mathrm{MPa} \cdot \mathrm{m}^{1 / 2}\right)\end{array}$ & $\begin{array}{c}\text { Cracked-body } \\
\mathrm{K}_{\mathrm{J}}^{\mathrm{s}}(\mathrm{J}) \\
\left(\mathrm{MPa}^{1 / 2} \mathrm{~m}^{1 / 2}\right.\end{array}$ \\
\hline \multicolumn{6}{|c|}{ Axially linear temperature distribution with $\Delta T=600^{\circ} \mathrm{C}$} \\
\hline 0.25 & 24.20 & 26.31 & 27.89 & 28.27 & 26.69 \\
\hline 0.50 & 33.24 & 35.66 & 38.72 & 38.30 & 34.76 \\
\hline 0.75 & 31.37 & 32.69 & 39.74 & 34.15 & 30.99 \\
\hline \multicolumn{6}{|c|}{ Radially linear temperature distribution with $\Delta T=200^{\circ} \mathrm{C}$} \\
\hline 0.25 & 24.14 & 27.17 & 34.26 & 28.79 & 29.04 \\
\hline 0.50 & 32.43 & 36.05 & 44.18 & 38.00 & 39.42 \\
\hline 0.75 & 31.02 & 35.79 & 43.15 & 35.72 & 31.71 \\
\hline \multicolumn{6}{|c|}{ Radially non-linear temperature distribution with $\Delta T=200^{\circ} \mathrm{C}$} \\
\hline 0.25 & 21.86 & 24.46 & 28.55 & 25.49 & 23.89 \\
\hline 0.50 & 27.30 & 30.45 & 33.47 & 31.15 & 30.46 \\
\hline 0.75 & 26.95 & 31.10 & 32.22 & 30.54 & 25.47 \\
\hline
\end{tabular}

Figure 3(a) shows that, for all of the temperature differences, the R6 inelastic route of equation (3) provides a conservative estimate of crack driving force, since the values of $\mathrm{K}(\mathrm{R} 6) / \mathrm{K}(\mathrm{FE})$ lie above unity, for the axially linear temperature case. $\mathrm{K}_{\mathrm{J}}^{\mathrm{s}}$ values from the elastic $\mathrm{R} 6$ route using equation (6) are compared to the FE cracked-body $\mathrm{K}_{\mathrm{J}}^{\mathrm{s}}$ values in Figure 3(b). The elastic R6 route also provides a conservative estimate of crack driving force.
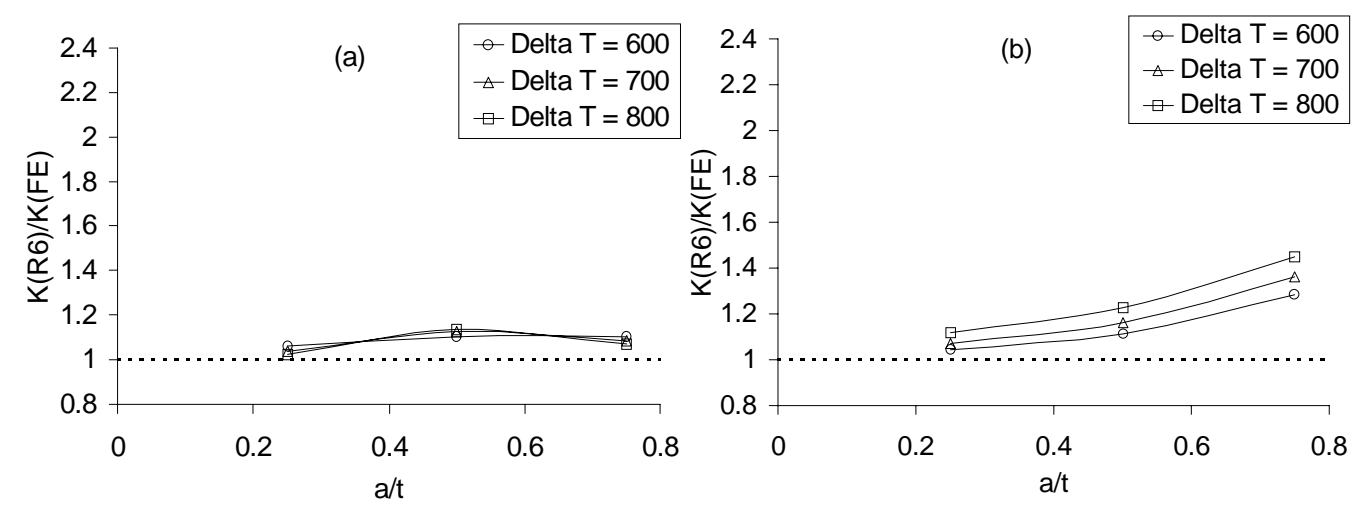

Figure 3: Comparison of (a) inelastic and (b) elastic uncracked-body R6 route $\mathrm{K}_{\mathrm{J}}^{\mathrm{s}}$ solutions with elastic-plastic cracked-body $\mathrm{FE} \mathrm{K}_{\mathrm{J}}^{\mathrm{s}}$ solutions, for axially-linear temperature distribution. 
Figure 4(a) shows the level of conservatism of the R6 inelastic route compared to the cracked-body results for the radially linear temperature case. For an a/t ratio of 0.5 at $\Delta \mathrm{T}$ of 200,300 and $400^{\circ} \mathrm{C}$, and for an a/t of 0.25 at $200^{\circ} \mathrm{C}$ and $300^{\circ} \mathrm{C}$, the $\mathrm{R} 6$ route is slightly unconservative. However, apart from these unconservatisms, the R6 inelastic route provides a conservative estimate for the crack driving force. $\mathrm{K}_{\mathrm{J}}^{\mathrm{s}}$ values derived from the elastic R6 route of equation (6) are compared to the $\mathrm{K}_{\mathrm{J}}^{\mathrm{s}}$ values from the cracked-body FE analyses in Figure 4(b). The elastic R6 route provides a consistently conservative estimate of crack driving force. As the temperature difference increases the conservatism of the elastic R6 route increases.
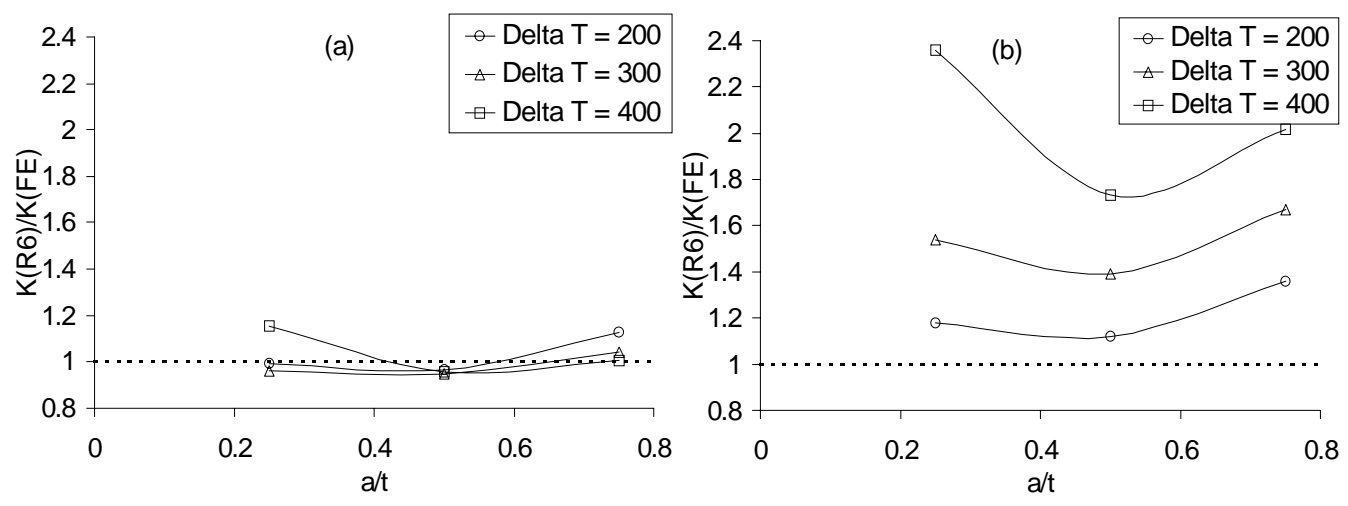

Figure 4: Comparison of (a) inelastic and (b) elastic uncracked-body R6 route $\mathrm{K}_{\mathrm{J}}^{\mathrm{s}}$ solutions with elastic-plastic cracked-body FE $\mathrm{K}_{\mathrm{J}}^{\mathrm{s}}$ solutions, for radially-linear temperature distribution.

Figure 5(a) shows the level of conservatism of the R6 inelastic route compared to the cracked-body FE data for the radially non-linear temperature case. For all of the temperature differences, the inelastic R6 route is conservative. In this case, the level of plasticity makes little difference to the level of conservatism. $\mathrm{K}_{\mathrm{J}}^{\mathrm{s}}$ values derived from the elastic R6 route of equation (6) are compared to the $\mathrm{K}_{\mathrm{J}}^{\mathrm{s}}$ values from the crackedbody FE results in Figure 5(b). The elastic R6 route is also conservative and as the temperature difference increases, the conservatism increases.

For the three loading conditions, the cracked-body CRIEPI driving force results are smaller and a maximum of about $8 \%$ different from those obtained 
from ABAQUS. This is true for all crack sizes analysed. It should be noted that the present analyses used a more refined mesh.

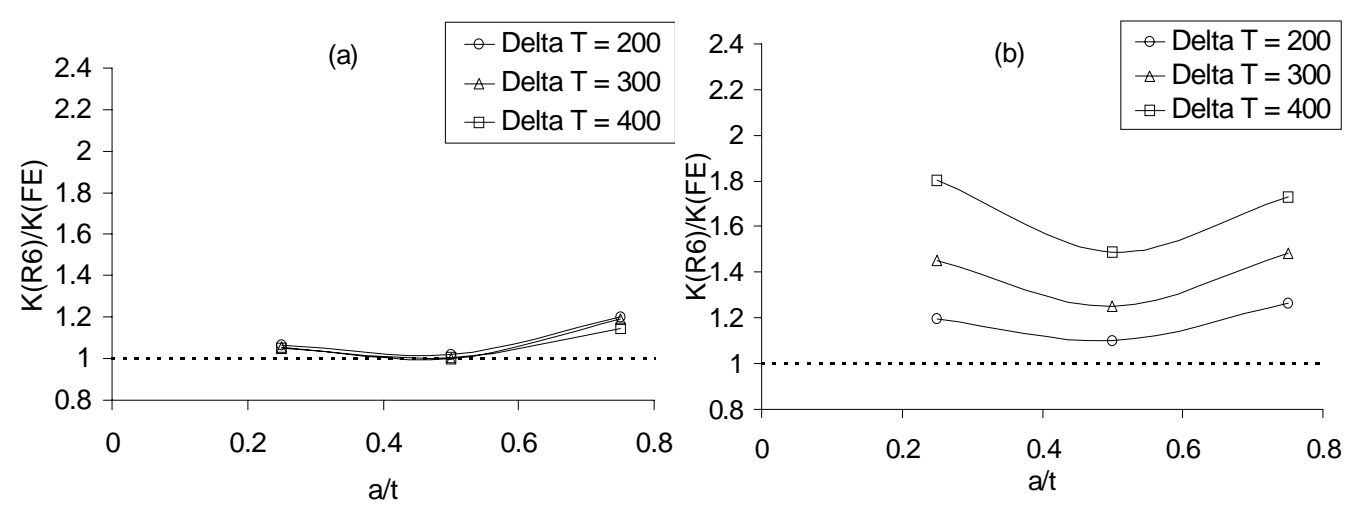

Figure 5: Comparison of (a) inelastic and (b) elastic uncracked-body R6 route $\mathrm{K}_{\mathrm{J}}^{\mathrm{s}}$ solutions with elastic-plastic cracked-body $\mathrm{FE} \mathrm{K}_{\mathrm{J}}^{\mathrm{s}}$ solutions, for radially non-linear temperature distribution.

\section{Part-circumferential external surface crack}

Table III shows the values of inelastic stress intensity factor from the R6 inelastic route and from the cracked-body route for the cylinder with a partcircumferential external crack loaded by a radially linear temperature distribution. The results are at the deepest point of the crack. All of the uncracked-body stress and strain data were obtained from the CRIEPI results. The R6 inelastic route is unconservative by about $3.7 \%$ when compared to the cracked-body CRIEPI value.

TABLE III: Values of $\mathrm{K}$ derived from R6 inelastic route and from cracked-body FE analysis. Cylinder with part-circumferential external surface crack

\begin{tabular}{|c|c|c|c|c|}
\hline 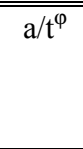 & $\begin{array}{c}\mathrm{K}_{\sigma}^{\mathrm{s}} \\
\left(\mathrm{MPa} \cdot \mathrm{m}^{1 / 2}\right)\end{array}$ & $\begin{array}{c}\mathrm{K}_{\varepsilon}^{\mathrm{s}} \\
\left(\mathrm{MPa} \cdot \mathrm{m}^{1 / 2}\right)\end{array}$ & $\begin{array}{c}\text { Elastic-plastic } \\
\mathrm{K}_{\mathrm{J}}^{\mathrm{S}} \\
\left(\mathrm{MPa} \cdot \mathrm{m}^{1 / 2}\right)\end{array}$ & $\begin{array}{c}\text { Cracked-body (CRIEPI) } \\
\mathrm{K}_{\mathrm{J}}^{\mathrm{S}}(\mathrm{J}) \\
\left(\mathrm{MPa}^{1 / 2} \mathrm{~m}^{1 / 2}\right)\end{array}$ \\
\hline \multicolumn{5}{|c|}{ Radially linear temperature distribution with $\Delta T=200^{\circ} \mathrm{C}$} \\
\hline 0.25 & 17.2 & 21.6 & 20.6 & 21.4 \\
\hline
\end{tabular}

\footnotetext{
${ }^{\varphi}$ Note that $\mathrm{a} / \mathrm{c}=0.5$.
} 


\section{CONCLUSIONS}

For the cylinder with a fully-circumferential internal crack:

1. The inelastic uncracked-body R6 route is conservative when the thermal load is applied as an axially linear or radially non-linear temperature distribution, for all crack sizes considered.

2. The inelastic uncracked-body R6 route is generally conservative when the thermal load is applied as a radially linear temperature distribution, but is slightly unconservative in some cases.

3. The elastic uncracked-body R6 route is conservative for all of the temperature distributions and crack sizes that were considered.

4. The CRIEPI cracked-body crack driving force results are consistently smaller and a maximum of about $8 \%$ different from those obtained from the ABAQUS cracked-body analyses.

For the cylinder with a part-circumferential external surface crack:

5. The inelastic R6 route is unconservative by about $3.7 \%$ for the case of thermal loading using a radially linear temperature distribution.

\section{ACKNOWLEDGEMENTS}

This paper is published by permission of British Energy Generation Ltd. The CRIEPI data presented have been obtained from the Komea Research Laboratory and the permission of CRIEPI to publish these results within this paper is gratefully acknowledged.

\section{REFERENCES}

1. R6 (2001) Assessment of the Integrity of Structures containing Defects, Revision 4, British Energy, Gloucester.

2. R6-Code (2001) Software for Assessing the Integrity of Structures containing Defects Version 4.1, British Energy, Gloucester.

3. ABAQUS/Standard (1998) Version 5.8, Hibbit, Karlson \& Sorensen, Inc., 1080 Main Street, Pawtucket, Rhode Island, USA. 